\section{Quality of life in Swedish children with congenital ichthyosis}

\author{
Agneta Gånemo \\ Department of Dermatology, Skåne \\ University Hospital, Malmö, Sweden
}

\begin{abstract}
Congenital ichthyosis encompasses a large group of keratinizing disorders with widespread scaling and a variable degree of erythema. Little is known about the quality of life in children with congenital ichthyosis and the impact of the disease on their family. Fifteen children aged 5-16 years with lamellar ichthyosis, Netherton's syndrome, epidermolytic hyperkeratosis or Harlequin ichthyosis, were investigated concerning the effect of their ichthyosis on their quality of life. This was measured with the established Children's Dermatology Life Quality Index (CDLOI), and the Dermatitis Family Impact questionnaire (DFI) modified by substituting the word ichthyosis for eczema. The questionnaires covered the preceding seven days and each had a maximum score of 30 : the higher the score, the greater the Quality of Life impairment. The median score was 9.0 (range 2-19) for the CDLQI and 9.0 (range 3-21) for DFI. There was a significant correlation between the DFI and the CDLOI scores. The item in the CDLQI questionnaire that showed the highest score was "itchy, scratchy, sore or painful skin" and the most highly scored item in the DFI questionnaire was effect on "housework, e.g. washing, cleaning"; both items related to the children's symptoms. The results of the study clearly establish that congenital ichthyosis impairs the quality of life of the affected children and their families.
\end{abstract}

\section{Introduction}

Congenital ichthyosis encompasses a heterogeneous group of hereditary skin disorders all of which are present at birth. ${ }^{1}$ After the neonatal period the affected children have widespread scaling and a variable degree of erythema or, in epidermolytic hyperkeratosis (EHK), extremely thickened skin and blisters over the body. ${ }^{2}$ In general, clinical examinations together with DNA tests confirm the diagnosis lamellar ichthyosis (LI), Netherton's syndrome (NS), EHK or Harlequin ichthyosis (HI). ${ }^{2}$ There is at present no cure for ichthyosis. The life-long treatment includes baths and daily applications of topical emollients and, for very severe symptoms, oral acitretin., ${ }^{3,4}$

Quality of life (QoL) studies in adults with ichthyosis have shown that their skin disease has affected them negatively and that the most problematic period has been their childhood. ${ }^{5,6}$ Many skin diseases in children have been associated with impaired QoL. ${ }^{7.8}$ Data on QoL in children with congenital ichthyosis are sparse. The aim of the present study was to investigate QoL in Swedish children with different forms of congenital ichthyosis and also the impact of the children's disease on the QoL of their families.

\section{Materials and Methods}

Children with the diagnosis of congenital ichthyosis aged 5-16 years were recruited in the years 2003-2007 through the Uppsala Genodermatosis Centre and the Swedish Ichthyosis Association. Inclusion criteria were a diagnosis from a dermatology clinic, age 5-16 years, command of the Swedish language, and oral and written informed consent. Fifteen children were enrolled in the study. Their diagnosis was based on clinical examination and in 7 cases it was further confirmed by DNA tests. The Research Ethics Committee of Uppsala University approved the study (03166).

QoL was assessed with the established questionnaires, Children's Dermatology Life Quality Index (CDLQI) ${ }^{9}$ and Dermatitis Family Impact questionnaire (DFI), ${ }^{10}$ in the Swedish language. The latter was modified with exchange of the word eczema for ichthyosis. The questionnaires covered the preceding seven days and each had 10 questions scoring $0-3$, giving a maximum score of 30 : the higher the score, the greater the impairment of QoL.

The author contacted the children's parents by telephone and study aim and design were explained. All agreed to participate. Information and a questionnaire about the child's medical history and present medical condition were mailed to the parents.

The children were investigated in their homes $(n=13)$ or at an annual meeting of the Swedish Ichthyosis Association $(n=2)$. The disease was rated by the investigator as mild, moderate, or severe, using a semi-quantitative global clinical assessment, based on degree of scaling, hyperkeratosis, erythema, and extension. After informed consent had been obtained and the severity of the ichthyosis had been scored, the parent(s) left the room and completed the DFI. The CDLQI was completed by the author and the child alone; the author asked the questions and filled in the child's answers. Statistical analysis was performed
Correspondence: Agneta Gånemo, Department of dermatology, Skåne University hospital, SE 20502 Malmö, Sweden.

E-mail: agneta.ganemo@skane.se

Key words: ichthyosis, Netherton's syndrome, Harlequin ichthyosis, Children's Dermatology Life Quality Index, skin disease.

Acknowledgments: I thank all the children and parents for their participation in this study. I also thank Fredrik Nilsson for help with medical statistics. The study was supported by grants from the Edvard Welander-Finsen Foundation, the Swedish Dermatological and Venereological Nursing Association, the First of May Flower Annual Campaign for Children's Health, and the Sunnerdahl Disability Foundation.

Conflict of interest: the author reports no conflicts of interest.

Received for publication: 18 August 2009.

Revision received: 24 March 2010.

Accepted for publication: 24 March 2010.

This work is licensed under a Creative Commons Attribution 3.0 License (by-nc 3.0).

(C) Copyright A. Gånemo, 2010

Licensee PAGEPress, Italy

Dermatology Reports 2010; 2:e7

doi:10.4081/dr.2010.e7

with the Software Platform version 2.4.1. ${ }^{11}$ Spearman's rank order correlation coefficient was computed as a measure of the association between CDLQI and DFI, and between the QoL results.

\section{Results}

Fifteen children ( 6 boys, 9 girls) aged 5-16 years (median 9 years) met the inclusion criteria LI $(n=10)$, NS $(n=3)$, EHK $(n=1)$ or HI $(n=1)$. Demographic and clinical characteristics of the participants are presented in Table 1. All patients were receiving some type of topical therapy for ichthyosis and 2 were being treated with oral acitretin.

\section{Quality of life}

The median total score for CDLQI was 9 (range 2-19). The three items in the CDLQI questionnaire that had the highest score were question 1 "itchy or painful skin", question 10 "treatment problems", and question 8 "calling you names, bullying or avoiding you". The median total score for DFI was 9 (range 3-21). The three items in the DFI questionnaire that were given the highest score were question 1 "effect on housework", question 10 "helping with the child's treatment", and question 6 
Table 1. Demographic and clinical characteristics of the children.

\begin{tabular}{|c|c|c|c|c|c|c|c|c|c|}
\hline Patient n. & $\begin{array}{l}\text { Sex/age } \\
\text { (y) }\end{array}$ & Diagnosis & $\begin{array}{l}\text { Global assessment } \\
\text { of disease severity }\end{array}$ & Hypohidrosis & $\begin{array}{l}\text { Ectropion/ } \\
\text { eye problems }\end{array}$ & Ear-problems & Pruritus & $\begin{array}{l}\text { Alopecial } \\
\text { abnormal hair }\end{array}$ & $\begin{array}{l}\text { Creams } \\
\text { containing }\end{array}$ \\
\hline 1 & $\mathrm{~F} / 5$ & $\mathrm{LI}$ & +++ & + & + & + & - & + & $\mathrm{L} / \mathrm{P}$ \\
\hline 2 & $\mathrm{~F} / 6$ & $\mathrm{LI}$ & +++ & + & + & + & - & - & $\mathrm{L} / \mathrm{P}$ \\
\hline 3 & $\mathrm{~F} / 7$ & $\mathrm{LI}$ & + & + & - & + & + & - & $\mathrm{P}+\mathrm{L} / \mathrm{P}$ \\
\hline 4 & $\mathrm{~F} / 7$ & $\mathrm{LI}$ & +++ & + & + & + & - & - & $\mathrm{L} / \mathrm{P}$ \\
\hline 5 & $\mathrm{~F} / 9$ & $\mathrm{LI}$ & ++ & + & + & - & - & - & $\mathrm{UL} / \mathrm{P}$ \\
\hline 6 & $\mathrm{M} / 9$ & $\mathrm{LI}$ & + & + & - & + & - & - & $\mathrm{L} / \mathrm{P}$ \\
\hline 7 & $\mathrm{M} / 12$ & LI & ++ & + & - & - & - & - & $\mathrm{L} / \mathrm{P}$ \\
\hline 8 & $\mathrm{M} / 13$ & LI & +++ & + & + & + & + & - & $\mathrm{U}+\mathrm{L} / \mathrm{P}$ \\
\hline 9 & $\mathrm{~F} / 14$ & LI & ++ & + & - & - & + & - & $\mathrm{BE}+\mathrm{GC}$ \\
\hline 10 & $\mathrm{~F} / 16$ & $\mathrm{LI}$ & + & + & - & + & - & - & $\mathrm{L} / \mathrm{P}$ \\
\hline 11 & $\mathrm{M} / 8$ & NS & ++ & + & - & + & + & + & BE \\
\hline 12 & $\mathrm{~F} / 11$ & NS & + & + & - & - & + & + & $\mathrm{U}+\mathrm{GC}$ \\
\hline 13 & $\mathrm{M} / 14$ & NS & +++ & - & - & - & - & + & $\mathrm{P}+\mathrm{GC}$ \\
\hline 14 & $\mathrm{M} / 13$ & EHK & +++ & + & - & + & - & - & U \\
\hline 15 & $\mathrm{~F} / 8$ & $\mathrm{HI}$ & +++ & + & - & + & - & + & $\mathrm{BE}$ \\
\hline
\end{tabular}

$\mathrm{Ns}=$ Netherton's syndrome, $\mathrm{LI}=$ Lamellar ichthyosis, $\mathrm{EHK}=$ Epidermolytic hyperkeratosis, HI= Harlequin ichthyosis. Global score of skin disease ' $+=$ Mild disease, $++=$ Moderate disease and $+++=$ Severe skin disease. Hypohidrosis, eye problems, ear problems, eczema/pruritus, Yes $=+$, No $=-$ Creams: $\mathrm{U}=$ urea, $\mathrm{L} / \mathrm{P}=$ lactic acid $/$ propylene glycol, $\mathrm{P}=$ propylene glycol, $\mathrm{BE}=$ bland emollient, $\mathrm{GC}=$ glucocorticoid.

"expenditure". There was a significant correlation between the DFI and CDLQI scores $(\mathrm{P}=$ 0.0048). The median and mean total scores for CDLQI and DFI for the children and for the two genders (male/female), for three age groups (5-8 years, 9-12 years and 13-16 years) and for different forms of ichthyosis are shown in Table 2 .

\section{Discussion}

This study of the impact of congenital ichthyosis on the QoL of afflicted children and of their families confirms that the ichthyosis affects both the children and the families. The observed impact on the children's QoL is in line with findings in two previous Swedish studies concerning adults with ichthyosis. ${ }^{5,6}$ The two items showing the highest CDLQI and DFI scores concern problems related to the children's ichthyosis symptoms and the treatment. In this study, it was shown that both the patients and their parents need support and help to cope with this chronic disease.

The mean total CDLQI score in this study was 9.0, which was higher than in a study presented as an abstract from France, where the total CDLQI score was 6.7. ${ }^{12}$ The present study comprised only children with congenital ichthyosis, while the French study included both congenital and non-congenital forms of the disease. It seems reasonable that patients with congenital ichthyosis, a more severe condition, will score higher than study groups of patients including both the more common types of ichthyosis and congenital ichthyosis.

Table 2. The total quality of life scores for CDLQI and DFI and the scores distributed by gender, age-groups and ichthyosis forms.

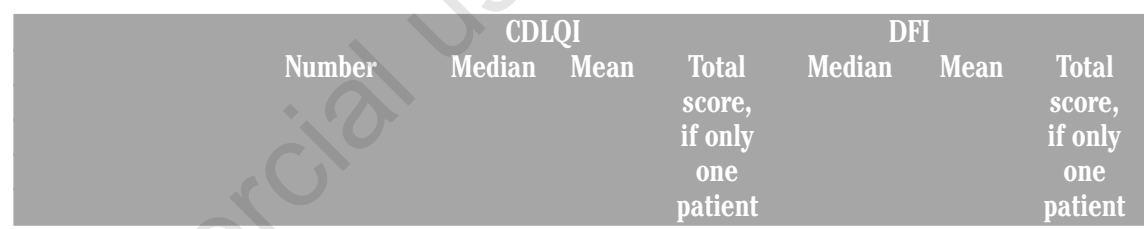

\begin{tabular}{lccccc} 
All & 15 & 9 & 9.3 & 9 & 9.0 \\
Sex (children) & & & & & \\
$\quad$ Male & 6 & 8.5 & 8.3 & 6.5 & 7.2 \\
Female & 9 & 9 & 9.4 & 10.0 & 70.7 \\
\hline
\end{tabular}

Age (children)

$\begin{array}{llllll}5-8 \text { years } & 6 & 13 & 13.3 & 12.5 & 12\end{array}$

$\begin{array}{llllll}9-12 \text { years } & 4 & 8 & 7.8 & 7.5 & 7.3\end{array}$

$13-16$ years

5

Ichthyosis

$\begin{array}{llllll}\text { Netherton's syndrome } & 3 & 8 & 10.3 & 9 & 9.7 \\ \end{array}$

$\begin{array}{llll}\text { Harlequin ichthyosis } & 1 & 16 & 14\end{array}$

Epidermolytic

Hyperkeratosis $\quad 1$

Parent (s) who completed the questionnaire

$\begin{array}{lcccc}\text { Both together } & 4 & & 6 & 6.8 \\ \text { Mother } & 10 & & 9 & 10 \\ \text { Father } & 1 & 17 & & \end{array}$

An important consideration is how representative our patients were. The number of patients in the present study group was small, but on the other hand the study included virtually all Swedish children with congenital ichthyosis in the age group in question. There was a small gender difference in CDLQI scores when the children themselves answered the questions and also a gender difference in the DFI scores when parent(s) answered (not significant) (Table 2). The children's ages influ- enced the CDLQI and DFI scores; a finding in line with results for children with eczema., ${ }^{7,13}$

In one study, ${ }^{14}$ the mother of an ichthyosis patient described her frustration about the shedding of her son's skin in their home. In that study, it was found that parents of children $(n=2)$ with ichthyosis also have an extra financial burden. This is in line with the findings in the present study concerning housework and the fact that the expenditure had an impact on their QoL. When children have a 
congenital disease, such as epidermolysis bullosa (EB) or congenital ichthyosis, they have their disease from birth to the end of their life. In a study comprising 30 children with different forms of $E B,{ }^{15}$ the total CDLQI scores were much higher than the total CDLQI scores in this study. On the other hand, the results of this study verify that ichthyosis causes greater impairment of QoL than other skin diseases in children. General questionnaires ${ }^{16}$ and many new studies are needed to compare the impact on QoL of ichthyosis with other congenital and chronic diseases.

In conclusion, this study showed that congenital ichthyosis considerably impaired the QoL of afflicted Swedish children and their families. Furthermore, the findings confirm the result of a previous interview study on older patients with congenital ichthyosis who described their childhood as the most problematic period in their lives.

\section{References}

1. Traupe H. The ichthyoses: a guide to clinical diagnosis, genetic counseling, and therapy. Berlin; New York: SpringerVerlag;1989.
2. DiGiovanna JJ, Robinson-Bostom L. Ichthyosis - Etiology, diagnosis, and management. A Clin Dermatol 2003;4:81-95.

3. Vahlquist A, Gånemo A, Virtanen M. Congenital ichthyosis: an overview of current and emerging therapies. Acta Derm Venereol 2008;88:4-14.

4. Ganemo A, Virtanen M, Vahlquist A. Improved topical treatment of lamellar ichthyosis: a double-blind study of four different cream formulations. Br J Dermatol 1999;141:1027-32.

5. Ganemo A, Lindholm C, Lindberg $M$, Sjoden P0, Vahlquist A. Quality of life in adults with congenital ichthyosis. J Adv Nursing 2003;44:412-9.

6. Ganemo A, Sjoden P0, Johansson E, et al. Health-related quality of life among patients with ichthyosis. Eur J Dermatol 2004;14:61-6.

7. Ganemo A, Svensson A, Lindberg M, Wahlgren CF. Quality of life in Swedish children with eczema. Acta Derm Venereol 2007;87:345-9.

8. Holm EA, Wulf HC, Stegmann H, Jemec GB. Life quality assessment among patients with atopic eczema. Br J Dermatol 2006;154:719-25.

9. Lewis-Jones MS, Finlay AY. The Children's Dermatology Life Quality Index (CDLQI): initial validation and practical use. $\mathrm{Br} \mathrm{J}$
Dermatol 1995;132:942-9.

10. Lawson V, Lewis-Jones MS, Finlay AY, et al. The family impact of childhood atopic dermatitis: the Dermatitis Family Impact Questionnaire. Br J Dermatol 1998;138: 107-13.

11. R Development Core team. R:A Language for statistical Computing. Foundation for statistical Computing 2006.

12. Blanchet-Bardon CC, J-M. Nguyen Le, C. Health-related quality of life in ichthyosis patients and family members. J Am Acad Dermatol. 2005;52(3, Supplement 1):P110.

13. Hon KL, Leung TF, Wong KY, Chow CM, Chuh A, Ng PC. Does age or gender influence quality of life in children with atopic dermatitis? Clin Exp Dermatol 2008;33: 705-9.

14. Basra MK, Finlay AY. The family impact of skin diseases: the Greater Patient concept. Br J Dermatol 2007;156:929-37.

15. Horn HM, Tidman MJ. Quality of life in epidermolysis bullosa. Clin Exp Dermatol 2002;27:707-10.

16. Beattie PE, Lewis-Jones MS. A comparative study of impairment of quality of life in children with skin disease and children with other chronic childhood diseases. $\mathrm{Br}$ J Dermatol 2006;155:145-51. 